\title{
Determination of Thickness of Smooth Geomembranes
}

\author{
Nazli Yesiller and Arif Cekic
}

\begin{abstract}
Tests were conducted to determine thickness of smooth, nonreinforced geomembranes using three methods: mechanical (according to ASTM and European standards), ultrasonic, and magnetic methods. The mechanical method is the standard procedure used for determining thickness of geomembranes. The ultrasonic and magnetic methods are not commonly used for geomembranes; however, they are used for testing other materials such as metals. Tests were conducted on 15 geomembranes representing five types of polymers (HDPE, LLDPE, PVC, PP, and EPDM). The results of the testing program indicated that the level of pressures applied affected the thickness measurements in mechanical tests. While the low pressures were not sufficient to flatten particularly the rigid geomembranes, the high pressures tended to compress the geomembranes excessively. Both high and low pressures prevented obtaining representative measurements. The measurements obtained using the ASTM method were more reliable than the measurements obtained with the European method, although it is believed that the most reliable measurements can be obtained by the nondestructive methods (ultrasonic and magnetic). These techniques are sensitive only to the thickness of the materials due to the inherent properties of the test procedures, and they work equally well for rigid and flexible geomembranes. Of the two nondestructive methods, ultrasonic testing is better due to several advantages: it allows for testing from the top surface of geomembranes in the laboratory or in the field, and it can be used on coupons of geomembranes as well as on whole sheets without the need for removing test samples. Both nondestructive methods can be improved for application to geomembranes.
\end{abstract}

Thickness is a basic property of geomembranes that is used for general identification and classification of these materials (Koerner 1997). Thickness is used in all phases of production and lifetime of geomembranes including manufacturing, design, and postfailure forensic analysis. Manufacturing quality control procedures include determination and verification of thickness (Daniel and Koerner 1995). Thickness measurements are needed to calculate the numerical values of properties, such as tensile strength. Thickness measurements are also used in the evaluation of degradation and endurance properties of geomembranes. In addition, properties of geomembranes including mechanical properties and resistance to transmission of fluids are affected by thickness (Giroud et al. 1994;

Park et al. 1995). Minimum required thicknesses are included in specifications for all applications of geomembranes.

This study was conducted to evaluate the effectiveness of existing mechanical methods and newly adapted ultrasonic and magnetic methods to determine the thickness of smooth, nonreinforced geomembranes. Reproducibility and repeatability of measurements obtained using different methods were determined. Comparisons were made between the thicknesses determined using the various methods, as well as thicknesses measured at various pressures using mechanical methods. The methods were rated using several parameters, and a comparison was provided which included comments about practical use of the thickness measurement setups and test procedures. Recommendations for determination of thickness are provided based on the results of the study.

\section{Thickness Measurement Techniques}

Mechanical Thickness Measurements

Mechanical thickness measurements consist of determination of the thickness of a geomembrane under a specific pressure. Geomembranes are placed horizontally in a thickness gage over a flat surface and a load is applied through a loading tip placed on the geomembrane. The magnitude of the applied load and 
the dimensions of the loading tip are set to induce a specific pressure on the geomembrane. Generally, the load is applied using a dead-weight loading mechanism. A schematic depiction of thickness measurement using a mechanical gage is presented in Fig. 1.

Mechanical thickness measurements are described in ASTM D5199-Standard Test Method for Measuring Nominal Thickness of Geotextiles and Geomembranes. The ASTM requirement is a pressure of $20 \mathrm{kPa}$ applied through a circular loading tip with a diameter of $6.35 \mathrm{~mm}$. A high pressure in the range of $50 \mathrm{kPa}$ to $200 \mathrm{kPa}$ is recommended to be used for HDPE geomembranes to overcome the rigidity of the material and obtain representative measurements. Tests are conducted on samples with a minimum dimension of $75 \mathrm{~mm}$ in diameter. Guidelines for mechanical thickness measurements are also provided in European standards (EN 964-1). In this case, pressures of $2 \mathrm{kPa}, 20 \mathrm{kPa}$, and $200 \mathrm{kPa}$ are applied using a circular tip with a diameter of $56.41 \mathrm{~mm}$. This arrangement requires significantly higher loads compared to the ASTM standard procedure, due to the increased loading tip area. Tests are conducted on samples with a minimum dimension of 1.75 times the diameter of the loading tip.

Determination of thickness of smooth geomembranes is usually simple and fast with mechanical thickness gages. The mechanical thickness gages are generally built to conduct tests on precut samples of geomembranes with relatively small dimensions (minimum 75-mm diameter for ASTM D5199, minimum 98-mm diameter for EN 964-1). Although larger gages that can accommodate sample sizes up to a few hundred millimeters can be constructed, the designs become impractical for larger sample sizes.

Mechanical thickness gages are generally bench-scale devices with a relatively smooth, horizontal surface required for the placement of the instrument. The mobility of these devices (for in-situ measurements) can be limited particularly when high loads to induce high pressures are required.

\section{Ultrasonic Thickness Measurements}

Determination of thickness is one of the most common applications of ultrasonic testing (McIntire 1991). Ultrasonic thickness gages are available that can be used for determination of thicknesses from fractions of a millimeter to more than a meter. Portable ultrasonic testing equipment is available that allows for testing in situ in addition to bench-scale devices. Thickness measurements are used for quality control and quality assurance purposes, as well as for monitoring the quality of materials during or after use.

Ultrasonic testing refers to mechanical wave propagation analyses conducted at frequencies higher than the audible sound range (>20 kHz). Generally, transmission of compression waves (primary or Pwaves) is used for thickness measurements. The thickness is determined as the multiplication of the Pwave propagation velocity in the test material and the travel time of the P-wave through the height (thickness) of the sample.

The ultrasonic pulse-echo method is used for testing materials such as metals, composites, and plastics. A schematic depiction of thickness measurement using the pulse-echo method is presented in Fig. 2. This method requires access to only one surface of the test material. Waves are sent and received by a single transducer placed on one surface of the test material. Tests can be conducted on precut samples of materials or at locations on rolls or sheets of materials without cutting and removing samples. The P-wave velocity in the test sample needs to be known to determine the thickness of the material. Published values are available for common materials including air, water, liquids, metals, and plastics. The velocity can be predetermined for materials tested less commonly (such as geomembranes) using preliminary ultrasonic measurements.

An ultrasonic test method to evaluate the condition of geomembranes was reported by Yesiller and Sungur (2001). The test method was partially based on ultrasonic thickness measurements that were used to detect damage and degradation in the geomembranes. This method was developed and tested in the laboratory. An application of ultrasonic testing to evaluate thickness of a geomembrane in the field was reported by Steffen and Asmus (1993). Problems were encountered during the installation of a polyethylene geomembrane in a waste disposal facility in Germany. The geomembrane had expanded and contracted due to temperature variations and was overstretched at locations near the anchor trenches. 
Local reductions in the thickness of the geomembrane were detected using ultrasonic tests. While details were not provided in the paper, it is believed that the pulse-echo inspection technique was used for thickness measurements. Velocity of wave transmission in the geomembrane was known, and this was used together with wave travel times obtained during testing to determine the thicknesses.

\section{Magnetic Thickness Measurements}

Determination of thickness is also a common application of magnetic testing. Test equipment is available for measuring thicknesses of both ferromagnetic and nonferromagnetic materials. Similar to ultrasonic applications, the thickness measurements are used for quality control and monitoring purposes.

Magnetic thickness measurements can be conducted using a variety of devices. Emphasis is placed on Hall Effect devices in this paper, since a magnetic thickness gage that operates on this principle is used for this study. The Hall Effect is a physical phenomenon that occurs in a material carrying an electric current subjected to a magnetic field. A potential difference is generated when the material carrying the electric current is placed in a magnetic field acting in the perpendicular direction. The potential difference occurs in a

direction perpendicular to the directions of both the electrical current and the magnetic field (Bray and McBride 1992).

A schematic depiction of thickness measurement using the magnetic method is presented in Fig. 3. The thickness is determined using the voltage difference generated by the presence of the test material placed between the probe and the target (small metal object). The presence of the test material affects the magnetic flux density generated between the magnet in the probe and the target. This difference is detected by the Hall Effect cell as a voltage differential and converted to a thickness measurement using results of preliminary calibration tests.

\section{Materials}

Tests were conducted on 15 geomembrane samples representing five polymer types with nominal thicknesses ranging from $0.76 \mathrm{~mm}$ to $2.5 \mathrm{~mm}$ (Table 1). Multiple samples of each geomembrane type were tested, except for EPDM. All of the samples were smooth, nonreinforced geomembranes. The test materials represent the most commonly used geomembranes (Koerner 1997).

\section{Testing Program}

The testing program consisted of determination of thickness of smooth geomembranes using mechanical, ultrasonic, and magnetic methods. Tests were conducted on specimens cut to the dimensions of $100 \mathrm{~mm} \mathrm{X} 100 \mathrm{~mm}$ to meet the requirements provided in both the ASTM and the European standards. The measurements were taken at the centerpoint of the specimens. The specimens were conditioned for $24 \mathrm{~h}$ at a temperature of $21^{\circ} \mathrm{C}$ and a relative humidity of $60 \%$ prior to testing. Equipment, Test Setups, and Procedures

The mechanical tests were conducted using a dead-weight loading system with interchangeable loads and loading tips. A photograph of the test setup is presented in Fig. $4 a$. The resolution of the dial gage was $0.001 \mathrm{~mm}$. For ASTM D5199 tests, pressures of 20

$\mathrm{kPa}, 50 \mathrm{kPa}, 100 \mathrm{kPa}, 150 \mathrm{kPa}$, and $200 \mathrm{kPa}$ were used. For EN 964-1 tests, pressures of $2 \mathrm{kPa}, 20 \mathrm{kPa}$, and $200 \mathrm{kPa}$ were used. The test setup was originally built for testing at $20 \mathrm{kPa}$ pressure according to the ASTM standard. Modifications were made to allow testing at higher pressures, and using the European standard. The modifications significantly increased the size and weight of the instrument and rendered the setup essentially immobile.

The ultrasonic tests were conducted using a commercially available thickness measurement system. The equipment consisted of a thickness gage and an ultrasonic transducer. A photograph of the setup is presented in Fig. 4b. Details for the components and the use of the equipment are described by Sungur (1999). Thicknesses can be determined with a resolution of $0.001 \mathrm{~mm}$ using this setup. 
In the ultrasonic tests, a measurement is made by placing the transducer on the top surface of a test specimen. A small amount of coupling material (in this case, water) is applied between the transducer and the specimen to eliminate air gaps and provide good contact between the sensor and the test material. A custom-made weight is placed on top of the transducer to ensure that the transducer is stable on the specimen and that it is in good contact with the geomembrane. A pressure of $19 \mathrm{kPa}$ is applied on a specimen by the ultrasonic setup. The ultrasonic setup that consists of the thickness gage and the transducer is small and mobile (Fig. 4b).

The P-wave velocities of the 15 geomembranes were determined prior to ultrasonic thickness measurements. A total of 864 tests were conducted on each geomembrane sample. This included measurements at a number of points on various specimens of a geomembrane sample and also repeated measurements at a given location by replacing the transducer at the location various times. Each ultrasonic measurement consisted of an average of 10 measurements increasing the data used for determination of the velocities to 8640 measurements per sample. While this is a significant number, it must be noted that the P-wave propagation occurs at time intervals measured in microseconds and the 10 average measurements are automatically recorded by the thickness gage. Generally, a single measurement (average of 10 readings) was completed in $30 \mathrm{~s}$, including the time required to move the transducer

TABLE 1-Test materials.

\begin{tabular}{lll}
\hline Sample & Polymer & $\begin{array}{c}\text { Nominal } \\
\text { Thickness, mm }\end{array}$ \\
\hline H1 & HDPE & 1.0 \\
H2 & HDPE & 1.5 \\
H3 & HDPE & 1.5 \\
H4 & HDPE & 2.5 \\
L1 & LLDPE & 0.76 \\
L2 & LLDPE & 1.5 \\
P1 & PVC & 1.0 \\
P2 & PVC & 1.0 \\
P3 & PVC & 1.0 \\
P4 & PVC & 1.5 \\
N1 & fPP & 1.0 \\
N2 & fPP & 1.0 \\
N3 & PP & 1.0 \\
N4 & fPP & 0.9 \\
E1 & EPDM $^{6}$ & 1.5 \\
\hline
\end{tabular}

\footnotetext{
${ }^{1}$ High density polyethylene

${ }^{2}$ Linear low density polyethylene

${ }^{3}$ Polyvinyl chloride

${ }_{5}^{4}$ Flexible polypropylene

${ }^{5}$ Polypropylene (less flexible)

${ }^{6}$ Ethylene propylene diene monomer
} 


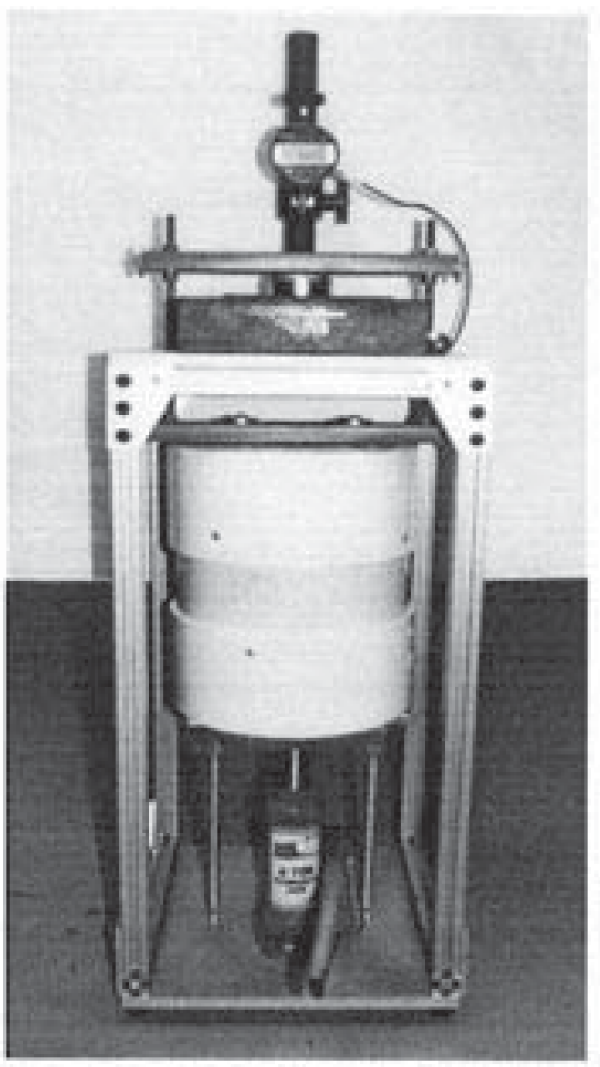

(a) Mechanical Test Setup

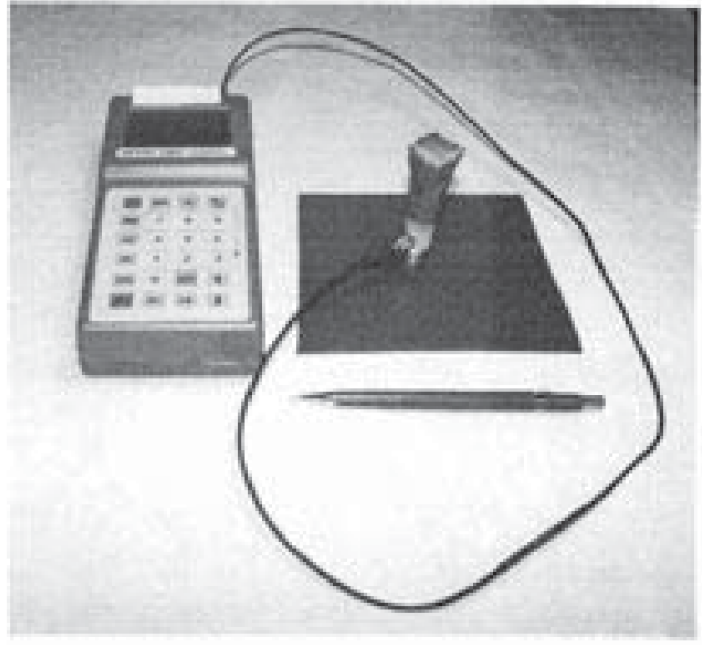

(b) Ulirasonic Test Setup

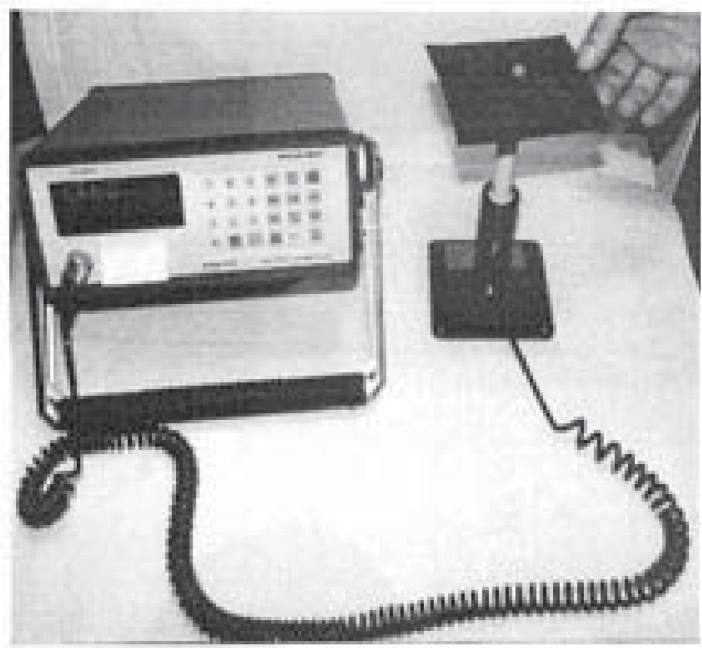

(c) Magnetic Test Setup

FIG. 4-Test equipment.

from one test location to the next. The velocities measured in this stage of testing had coefficient of 
variations less than $0.3 \%$ for all the samples. It would be possible to establish the velocity for a geomembrane using substantially less measurements, as the variation in the velocities is small.

In the preliminary tests, the thicknesses of geomembranes and the travel time of P-waves were used to determine the P-wave velocities. The thickness measurements were made using a mechanical thickness gage under a pressure that represented the pressure applied by the ultrasonic transducer and the attached load on a specimen. This pressure $(19 \mathrm{kPa})$ was generally insufficient to obtain representative measurements, particularly for rigid geomembranes, and extra pressure was applied manually. The specimens were pressed against the flat measurement surface around the loading tip, and a measurement was recorded when the value indicated by the dial gage stabilized under the pressing action. It is believed that representative thickness measurements were obtained this way.

The magnetic tests were conducted using a commercially available Hall Effect thickness gage (Fig. $4 c$ ). The setup consists of a cylindrical probe and a spherical target with a diameter of $5 \mathrm{~mm}$ and a mass of $0.432 \mathrm{~g}$. Thicknesses can be determined with a resolution of $0.001 \mathrm{~mm}$ using this setup. This particular setup is commonly used for taking thickness measurements of hard-to-reach locations, such as tight corners and grooved areas. For example, in determining the thickness of molded plastic bottles, the target ball is dropped in the bottle and the measurement is done by dragging the ball to the desired measurement location with the probe. In the tests for this study, the specimen was held above the probe at the center, and the target ball was dropped on the specimen to conduct the measurement. The central axis through the ball and the probe needs to be orthogonal to the specimen to obtain representative measurements of thickness. This setup is moderate in size and mobile, which allows for testing both in the laboratory and in the field. However, unlike the ultrasonic setup, access to both sides of a geomembrane is required.

Thickness Tests

The first set of tests was conducted on 30 specimens cut from the 15 geomembrane samples presented in Table 1. A total of 10 thickness measurements was obtained on each specimen using the mechanical ( 5 pressure levels for ASTM, 3 pressure levels for European), ultrasonic, and magnetic test setups. The initial set of tests allowed for determination of the thickness of geomembranes and also comparison of the results obtained using the different measurement techniques. A second set of tests was conducted on a single specimen of all 15 geomembrane samples by obtaining 30 measurements on the same location on the specimen, using the 10 different test methods ( 8 mechanical, 1 ultrasonic, 1 magnetic). These tests were used to determine the repeatability of thickness measurements. Overall, a total of 9000 thickness measurements were made for this test program.

\section{Results and Discussion}

Initially, the thicknesses of the geomembranes determined using the mechanical, ultrasonic, and magnetic methods are presented. Comparisons of the measurements obtained by the different methods are presented subsequently. This is followed by presentation of the repeatability measurements. Then comments about general use and practicality of the methods are provided.

Geomembrane Thicknesses

The thickness measurements obtained by mechanical, ultrasonic, and magnetic methods are presented in Table 2. The measurements were obtained on 30 specimens of each geomembrane sample, and the average of the 30 thickness measurements (AVG), the corresponding standard deviations (SD), and the coefficient of variations (COV) are presented in the table. The results are also presented in Fig. 5.

The thickness of the samples generally decreased with increasing pressures in the mechanical tests. This decrease was particularly pronounced between $20 \mathrm{kPa}$ and $50 \mathrm{kPa}$ in ASTM tests, and between 2 $\mathrm{kPa}$ and $20 \mathrm{kPa}$ in EN tests. The amount of decrease was less at the higher pressures for both methods. Also, the decrease was more for the polyethylene samples compared to the other geomembranes. Significantly lower thicknesses were measured at higher pressures and using the nondestructive test methods (Table 2, Fig. 5).

The standard deviations for rigid geomembranes are higher than the standard deviations for flexible geomembranes (Table 2). This is particularly noticeable for mechanical measurements (both ASTM and EN) obtained at low pressures. The standard deviations and the differences in standard deviations 
between rigid and flexible geomembranes decrease at high pressures. The coefficient of variations also decreases at high pressures. The standard deviations and coefficient of variations are generally low for the ultrasonic and the magnetic measurements.

\section{Comparison of Methods}

Comparisons were made to determine whether the thicknesses measured using the various methods were statistically similar. The analysis of variance procedures (ANOVA) and Tukey analysis were used (Mendenhall and Sincich 1995; Milliken and Johnson 1984). Initially, two-way ANOVA analysis was used to compare all 10 measurement procedures at a 95\% significance level. The two-way analysis allowed for the determination of the measurement method and geomembrane type effects on the measured thicknesses. This analysis indicated that there were differences in the thickness measurements.

The Tukey analysis was used to identify the statistically dissimilar data. The Tukey analysis consisted of a pairwise comparison of all of the measurement procedures for all of the geomembranes. The results of this analysis are presented in Table 3. Table 3 includes 45 comparisons for 15 geomembrane types ( 675 cells) that consist of the comparisons within the mechanical measurement methods, and between the mechanical, ultrasonic, and magnetic methods. The notation " $A$ " represents methods that provide significantly different values for thickness, and the notation " $\mathrm{B}$ " represents methods that provide similar values for thickness. The comparisons are summarized for each column representing all comparisons for a single geomembrane type, as well as for each row representing a single comparison for all geomembrane types (Table 3). A complete summary is provided at the lower right corner of the table for all geomembrane types and all comparisons.

The data in Table 3 indicate that $81 \%$ of the comparisons are statistically different and $19 \%$ of the comparisons are statistically similar. Overall, the number of methods that provide similar results is low. The factors in the determination of similarity are the thickness values, and also the standard deviations and coefficient of variations for individual test methods. High differences in thickness values and/or low standard deviations and coefficient of variations result in significant differences between methods (Table 2, Table 3).

The highest similarity exists within the ASTM method. The thicknesses obtained using $150 \mathrm{kPa}$ and $200 \mathrm{kPa}$ pressures are similar for all geomembrane types. This is followed by 50 and $100 \mathrm{kPa}$ measurements that are similar for 12 types of geomembranes. The comparisons for $50-150 \mathrm{kPa}, 50-$ $200 \mathrm{kPa}, 100-150 \mathrm{kPa}$, and $100-200 \mathrm{kPa}$ are similar for 10 types of geomembranes. The thicknesses determined at the low ASTM pressure $(20 \mathrm{kPa})$ are generally not similar to the thicknesses determined at higher pressures. There are no similarities within the measurements made using the European standard. Also, there are no similarities between the measurements obtained at the same pressure levels (20 kPa and $200 \mathrm{kPa}$ ) using the ASTM and EN methods. The values obtained using the European standard were lower than the thicknesses determined using the ASTM method for both pressure levels $(20 \mathrm{kPa}$ and $200 \mathrm{kPa}$ ). These values were also lower than the measurements obtained using the ultrasonic and magnetic methods (Table 2).

While the similarities for flexible geomembranes are somewhat higher than the similarities for rigid geomembranes, overall, the number of methods that provide similar data for flexible geomembranes is not high. For flexible geomembranes, $60 \%$ to $91 \%$ of the comparisons are significantly different (Table 3 ).

\section{Repeatability of Measurements}

The results of the repeatability tests are presented in Table 4 . These tests consisted of 30 repetitions of the mechanical, ultrasonic, and magnetic tests on a single specimen of each geomembrane sample. The average of the 30 thickness measurements (AVG), the corresponding standard deviations (SD), and the coefficient of variations (COV) are presented in the table. It was observed that the coefficient of variations was less than $1 \%$, with the majority of values less than $0.5 \%$. The COVs were somewhat higher at low mechanical pressures, compared with the high pressures. This is especially true for the rigid geomembranes such as polyethylene.

The highest variations were observed for the magnetic measurements. Holding the specimen perfectly orthogonal to the small 
TABLE 2-Results of thickness tests.

(a) Mechancal Tests-ASTM D5199

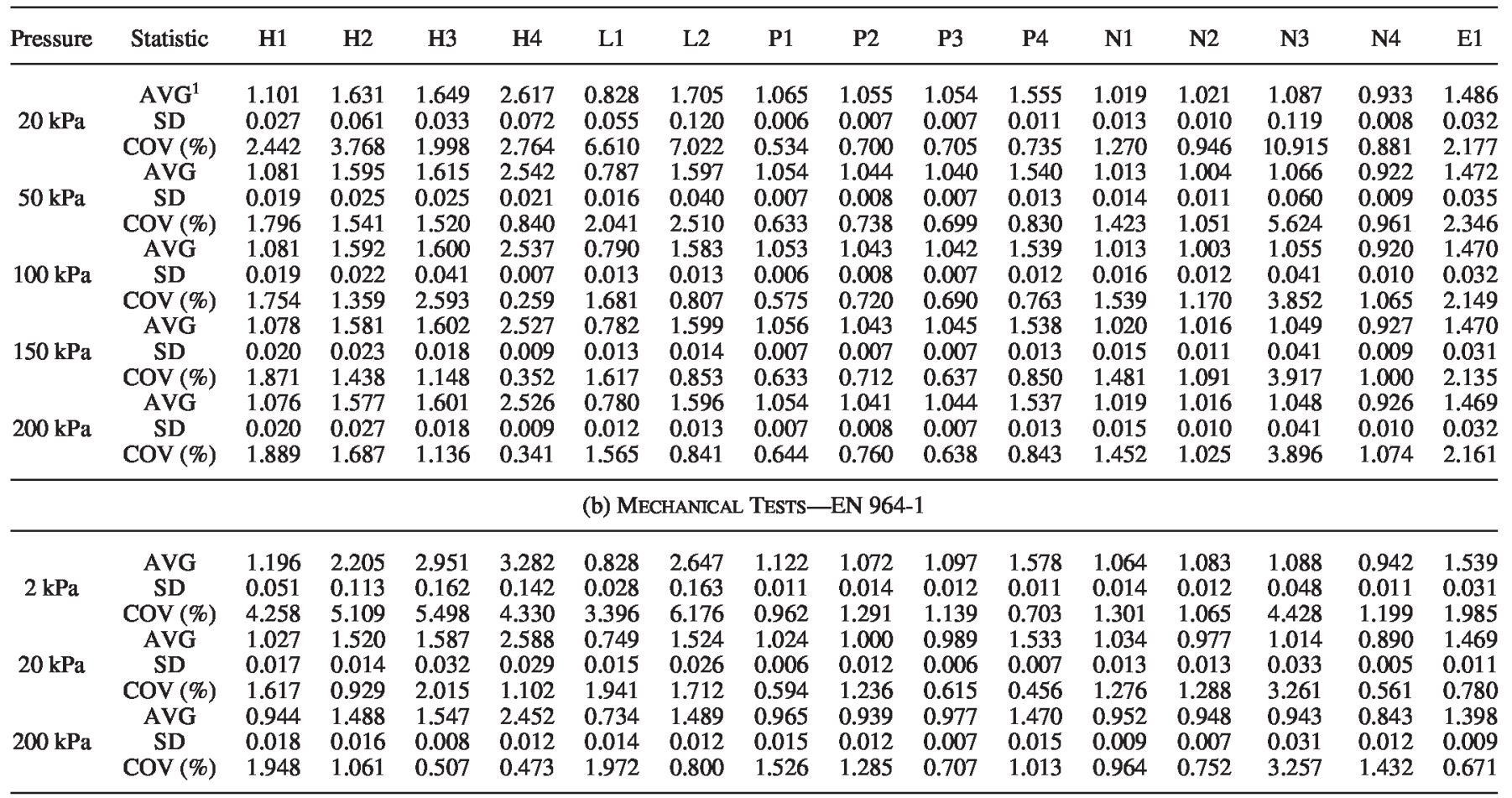

(c) Ultrasontc Tests

\begin{tabular}{|c|c|c|c|c|c|c|c|c|c|c|c|c|c|c|c|}
\hline Statistic & H1 & $\mathbf{H} 2$ & H3 & H4 & $\mathrm{L} 1$ & $\mathrm{~L} 2$ & P1 & $\mathbf{P} 2$ & P3 & P4 & N1 & N2 & N3 & N4 & E1 \\
\hline AVG & 1.115 & 1.619 & 1.596 & 2.567 & 0.820 & 1.626 & 1.055 & 1.057 & 1.055 & 1.560 & 1.020 & 1.021 & 1.073 & 0.942 & 1.461 \\
\hline SD & 0.022 & 0.024 & 0.022 & 0.023 & 0.016 & 0.016 & 0.007 & 0.009 & 0.007 & 0.013 & 0.015 & 0.014 & 0.045 & 0.010 & 0.035 \\
\hline
\end{tabular}

(d) Magnetic Tests

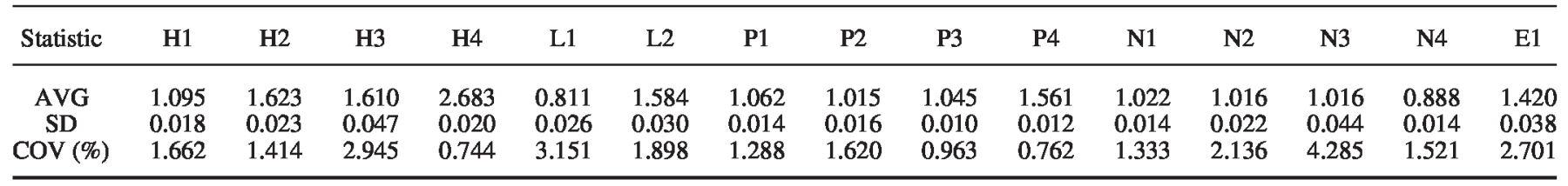

\footnotetext{
${ }^{1}$ All thickness measurements are in mm.
} 


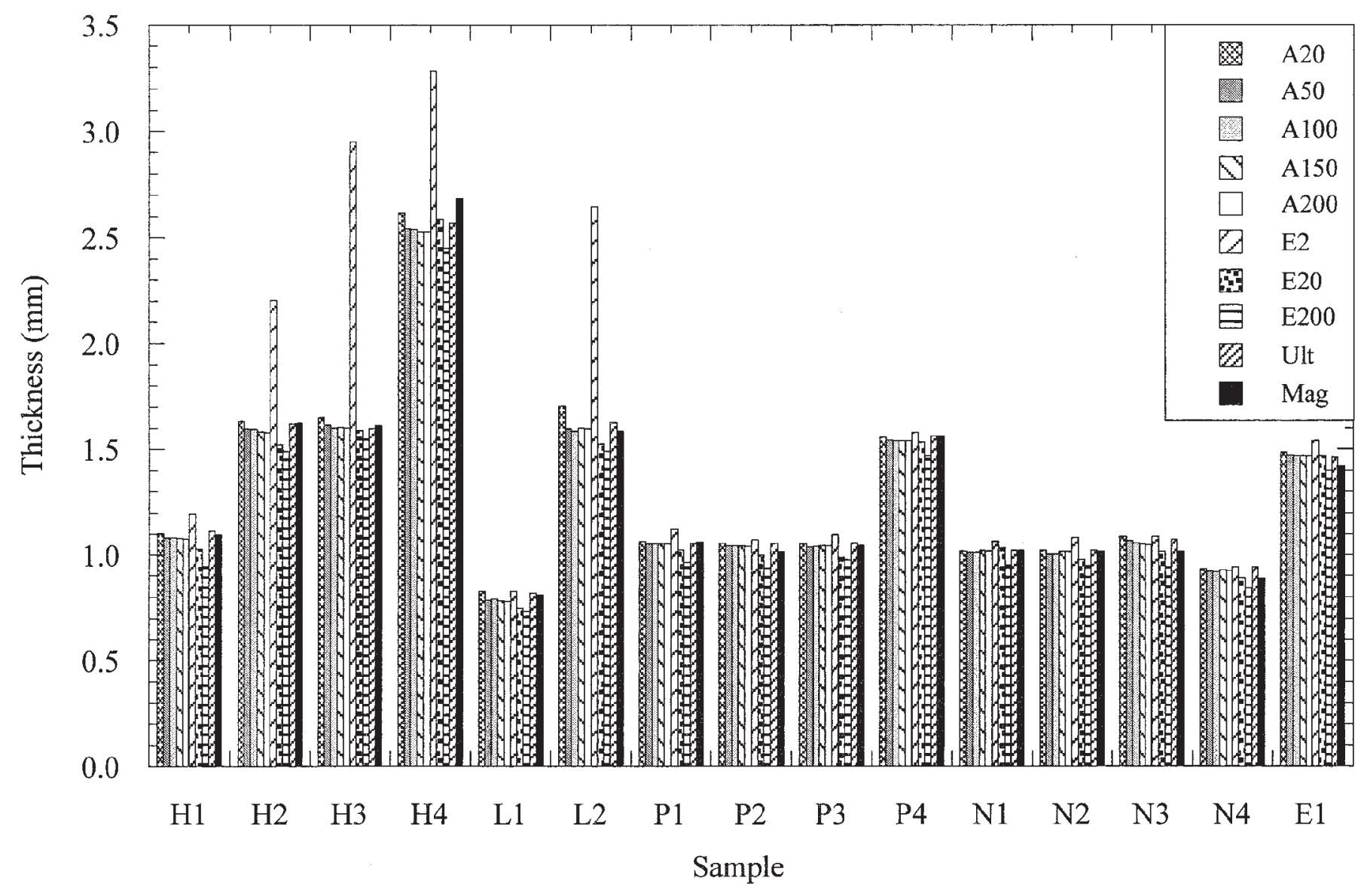

FIG. 5-Thicknesses of samples.

probe tip and maintaining the $90^{\circ}$ angle during the placement of the ball, and then during the measurement, is difficult. It is believed that this caused the slightly higher variations in these measurements. Nevertheless, the repeatability of all of the test methods is good, and there are no significant differences between the methods based on quality of repeatability.

\section{Critique of Thickness Measurement Methods}

Several qualitative observations were made during the thickness measurements that are related to the practical use of the various methods. Also, there are inherent differences between the test methods that need to be discussed further.

Problems existed both at the low and high pressure levels for mechanical tests. Mechanical measurements are based on the application of a certain pressure through a specific loading tip. It is difficult to identify the optimum combination of load and loading tip that would work for both flexible and rigid geomembranes.

At low pressure levels, it was observed that the pressure applied to the specimens was not sufficient to flatten the specimens and obtain good contact between the loading tip, specimen, and the base of the thickness gage, particularly for rigid geomembranes. On the other hand, an imprint of the loading tip was left after the tip was lifted from the specimens at high pressure levels, particularly with European standard measurements. While the deformation of the specimens was not permanent, this indicated that the specimens were compressed during the measurements, leading to unrepresen tatively low values for thicknesses. In addition, the thicknesses obtained using the EN method were significantly lower than the values obtained using the ASTM method at the same pressure levels ( $20 \mathrm{kPa}$ and $200 \mathrm{kPa}$ ). In fact, the $20 \mathrm{kPa}$ EN measurements were generally lower than the ASTM measurements at higher pressures (Table 2). At the same pressure levels $(20 \mathrm{kPa}$ and $200 \mathrm{kPa})$, a larger area on a geomembrane was subjected to the applied stress in the EN method, compared with the ASTM method. 
The larger contact area for vertical stress caused greater deformation at the center of the test material. An imprint of the EN probe tip was left on the geomembranes after a measurement using $20 \mathrm{kPa}$ or 200 $\mathrm{kPa}$ pressure was made. Such excessive deformation was not observed with the ASTM method.

It is believed that the most reliable measurements can be obtained by the nondestructive test methods. The ultrasonic method is based on the transmission of high frequency mechanical waves through a test material. The wave transmission is affected only by the thickness of the test material (Fig. 2). The magnetic method is based on the measurement of the changes in a magnetic field due to the placement of a test material in the field. The thickness of the material causes the changes in the magnetic field (Fig. 3 ). These methods are not sensitive to the type of the geomembranes (flexible or rigid), and they do not produce any effects on the specimens. In addition, data acquisition procedures are simpler for the nondestructive methods. Data can be stored and analyzed in both the ultrasonic and magnetic gages, and also the stored data can be easily transferred to a computer for further analysis. Warnings can be set 
TABLE 3-Comparison of thickness measurement methods.

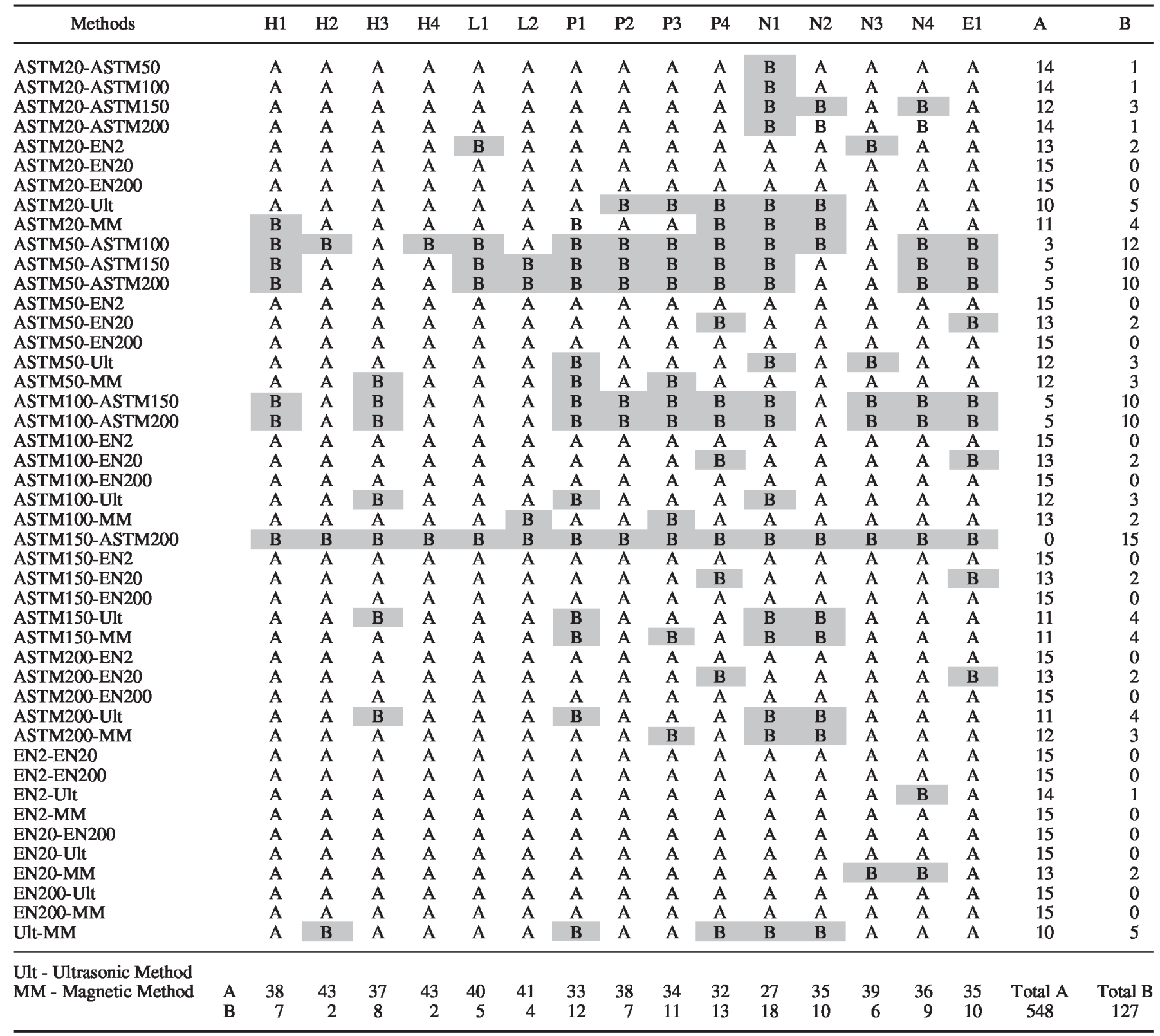

up in data acquisition systems that would alert the operator to the presence of out-of-range data during measurements.

However, it must be noted that there were shortcomings in the nondestructive procedures used for this study. The magnetic setup used for this analysis is made for testing hard-to-reach locations of different sized and shaped materials. While it allows for testing such locations, it is difficult to maintain the optimum placement of the sheet materials tested in this study in this particular setup. There were problems with holding the specimen at $90^{\circ}$ angle during a thickness measurement. A different setup can be used to obtain better measurements that minimizes the effects of operator handling. The preliminary ultrasonic tests can be improved by determining the velocity of the test materials using calibration sheets or blocks with known thicknesses. Geomembrane manufacturers can produce calibration blocks/sheets with known thicknesses for determination of velocities. Calibration blocks are used commonly in ultrasonic testing of metals and other materials (McIntire 1991). 
Performance Evaluation of Test Methods

The effectiveness of the test methods are evaluated using various criteria presented throughout the paper. A summary of these criteria is presented in Table 5. The overall performance ranking of the methods (Table 6) is based on the evaluation criteria presented in Table 5. The ranking is determined by counting the number of "high," "medium," and "low" scores given to each test procedure. The results provided three rankings: "excellent" that indicates the most effective test method resulting in most representative measurements, "good" indicating reasonably representative measurements, and "poor" that indicates essentially unrepresentative mea-

TABLE 4-Results of repeatability tests.

\begin{tabular}{|c|c|c|c|c|c|c|c|c|c|c|c|c|c|c|c|c|}
\hline Method & Statistic & H1 & $\mathrm{H} 2$ & H3 & H4 & L1 & L2 & P1 & P2 & $\mathbf{P 3}$ & P4 & N1 & $\mathrm{N} 2$ & N3 & N4 & E1 \\
\hline & AVG & 1.100 & 1.604 & 1.625 & 2.551 & 0.827 & 1.605 & 1.068 & 1.049 & 1.052 & 1.541 & 1.002 & 1.032 & 1.150 & 0.931 & 1.513 \\
\hline \multirow[t]{2}{*}{ ASTM20 } & SD & 0.004 & 0.002 & 0.004 & 0.002 & 0.003 & 0.004 & 0.001 & 0.002 & 0.002 & 0.001 & 0.001 & 0.001 & 0.001 & 0.001 & 0.001 \\
\hline & AVG & 1.087 & 1.583 & 1.619 & 2.567 & 0.796 & 1.585 & 1.064 & 1.038 & 1.040 & 1.523 & 1.006 & 1.023 & 1.148 & 0.917 & 1.498 \\
\hline \multirow[t]{3}{*}{ ASTM50 } & SD & 0.001 & 0.001 & 0.001 & 0.001 & 0.001 & 0.001 & 0.001 & 0.001 & 0.001 & 0.001 & 0.001 & 0.001 & 0.001 & 0.001 & 0.001 \\
\hline & $\operatorname{cov}(\%)$ & 0.102 & 0.071 & 0.048 & 0.039 & 0.105 & 0.041 & 0.065 & 0.083 & 0.137 & 0.033 & 0.080 & 0.093 & 0.055 & 0.084 & 0.037 \\
\hline & AVG & 1.082 & 1.581 & 1.604 & 2.525 & 0.793 & 1.581 & 1.055 & 1.035 & 1.040 & 1.521 & 1.000 & 1.018 & 1.138 & 0.917 & 1.498 \\
\hline ASTM100 & AVG & 1.082 & 1.573 & 1.603 & 2.536 & 0.792 & 1.597 & 1.060 & 1.033 & 1.041 & 1.522 & 1.002 & 1.022 & 1.128 & 0.921 & 1.496 \\
\hline \multirow[t]{3}{*}{ ASTM150 } & SD & 0.001 & 0.001 & 0.001 & 0.000 & 0.001 & 0.001 & 0.001 & 0.001 & 0.001 & 0.001 & 0.001 & 0.001 & 0.001 & 0.001 & 0.001 \\
\hline & $\operatorname{COV}(\%)$ & 0.076 & 0.049 & 0.053 & 0.017 & 0.087 & 0.031 & 0.079 & 0.061 & 0.135 & 0.068 & 0.123 & 0.099 & 0.073 & 0.068 & 0.048 \\
\hline & AVG & 1.079 & 1.570 & 1.597 & 2.540 & 0.787 & 1.601 & 1.059 & 1.028 & 1.040 & 1.521 & 0.999 & 1.026 & 1.123 & 0.915 & 1.497 \\
\hline \multirow[t]{3}{*}{ ASTM200 } & SD & 0.001 & 0.001 & 0.001 & 0.001 & 0.000 & 0.001 & 0.001 & 0.001 & 0.001 & 0.001 & 0.001 & 0.000 & 0.001 & 0.001 & 0.001 \\
\hline & $\operatorname{COV}(\%)$ & 0.083 & 0.052 & 0.052 & 0.035 & 0.062 & 0.049 & 0.063 & 0.140 & 0.137 & 0.060 & 0.068 & 0.042 & 0.120 & 0.076 & 0.068 \\
\hline & $\mathrm{AVG}$ & 1.185 & 2.820 & 3.380 & 3.708 & 0.848 & 2.885 & 1.087 & 1.083 & 1.132 & 1.593 & 1.062 & 1.084 & 1.197 & 0.951 & 1.550 \\
\hline EN 20 & AVG & 0.970 & 1.516 & 1.551 & 2.461 & 0.744 & 1.514 & 0.969 & 0.949 & 0.969 & 1.458 & 0.939 & 0.954 & 0.954 & 0.856 & 1.409 \\
\hline \multirow[t]{3}{*}{ EN 200} & SD & 0.001 & 0.001 & 0.001 & 0.001 & 0.001 & 0.001 & 0.001 & 0.001 & 0.000 & 0.001 & 0.001 & 0.000 & 0.001 & 0.001 & 0.000 \\
\hline & $\operatorname{COV}(\%)$ & 0.117 & 0.079 & 0.056 & 0.034 & 0.126 & 0.072 & 0.120 & 0.120 & 0.050 & 0.057 & 0.054 & 0.051 & 0.090 & 0.092 & 0.035 \\
\hline & AVG & 1.127 & 1.629 & 1.597 & 2.579 & 0.829 & 1.661 & 1.060 & 1.050 & 1.061 & 1.548 & 1.002 & 1.046 & 1.146 & 0.945 & 1.516 \\
\hline \multirow[t]{3}{*}{ Ultrasonic } & SD & 0.001 & 0.001 & 0.001 & 0.001 & 0.002 & 0.003 & 0.003 & 0.003 & 0.004 & 0.003 & 0.003 & 0.004 & 0.003 & 0.004 & 0.004 \\
\hline & $\operatorname{COV}(\%)$ & 0.083 & 0.046 & 0.059 & 0.055 & 0.229 & 0.184 & 0.308 & 0.239 & 0.343 & 0.168 & 0.332 & 0.343 & 0.256 & 0.431 & 0.247 \\
\hline & AVG & 1.094 & 1.646 & 1.602 & 2.661 & 0.793 & 1.596 & 1.041 & 1.017 & 1.037 & 1.528 & 0.999 & 1.015 & 1.075 & 0.886 & 1.437 \\
\hline \multirow[t]{2}{*}{ Magnetic } & SD & 0.006 & 0.006 & 0.007 & 0.005 & 0.007 & 0.005 & 0.005 & 0.005 & 0.004 & 0.006 & 0.008 & 0.004 & 0.007 & 0.005 & 0.007 \\
\hline & $\operatorname{COV}(\%)$ & 0.533 & 0.346 & 0.447 & 0.200 & 0.841 & 0.303 & 0.443 & 0.457 & 0.387 & 0.379 & 0.776 & 0.369 & 0.659 & 0.513 & 0.454 \\
\hline
\end{tabular}


TABLE 5-Performance evaluation criteria.

\begin{tabular}{|c|c|c|c|}
\hline \multirow{2}{*}{$\begin{array}{l}\text { Criteria } \\
\text { Suitability for } \\
\text { geomembrane } \\
\text { testing }\end{array}$} & \multicolumn{3}{|c|}{ Score } \\
\hline & Low & Medium & High \\
\hline $\begin{array}{l}\text { Simplicity of } \\
\text { operation }\end{array}$ & Low & Medium & High \\
\hline $\begin{array}{l}\text { Portability } \\
\text { (Lab/field } \\
\text { measurements) }\end{array}$ & Low & Medium & High \\
\hline $\begin{array}{l}\text { Surface access } \\
\text { requirement }\end{array}$ & $\begin{array}{l}\text { Low } \\
\text { (Two-sides) }\end{array}$ & - & $\begin{array}{l}\text { High } \\
\text { (One-side) }\end{array}$ \\
\hline Specimen type & $\begin{array}{l}\text { Low } \\
\text { (Coupon) }\end{array}$ & - & $\begin{array}{l}\text { High } \\
\text { (Coupon/sheet) }\end{array}$ \\
\hline Precision & Low & Medium & High \\
\hline Repeatability & Low & Medium & High \\
\hline Pressure & $\begin{array}{l}\text { Low } \\
\text { (Insufficient/ } \\
\text { excessive) }\end{array}$ & $\begin{array}{l}\text { Medium } \\
\text { (Appears } \\
\text { sufficient) }\end{array}$ & $\begin{array}{l}\text { High } \\
\text { (Pressure } \\
\text { not required) }\end{array}$ \\
\hline $\begin{array}{l}\text { Effect on test } \\
\text { specimen }\end{array}$ & $\begin{array}{l}\text { Low } \\
\quad \text { (Large effect) }\end{array}$ & $\begin{array}{l}\text { Medium } \\
\quad \text { (Some effect) }\end{array}$ & $\begin{array}{l}\text { High } \\
\text { (No effect) }\end{array}$ \\
\hline
\end{tabular}

surements. In addition to the ranking, comments about the measurement techniques are also presented in Table 6.

The lowest pressures for both ASTM and EN methods received "poor" ranking, as it was observed that artificially high thickness measurements were obtained using these methods. This was particularly noticeable for rigid geomembranes. The $20 \mathrm{kPa}$ and $200 \mathrm{kPa}$ pressures for EN measurements also received poor ratings, as it is believed that unrepresentative low thickness values were obtained at these pressures. The combination of the large loading tip and the applied stresses compressed the specimens excessively, leading to artificially low thickness values.

The ASTM tests at $50 \mathrm{kPa}$ to $200 \mathrm{kPa}$ pressures received good ratings. It is believed that reasonably representative and comparable measurements were obtained at these pressures (Table 3). The mechanical measurements received low scores for the high dependency on the applied pressure, the requirement for access to two sides of a specimen, the need for coupon specimens for measurements, and the large size of the test setup required to apply high pressures.

The nondestructive measurements are fast, easy, and provide as high resolution and repeatability as the mechanical measurements. Additionally, the nondestructive methods do not require application of pressure or produce any effects on test materials. The magnetic method was ranked "good," producing reasonably representative measurements. The main shortcoming of the setup used for the study was related to maintaining the optimum specimen position during a measurement. Also, "low" scores were given for access required to two sides of a specimen and the requirement for mainly coupon specimen type.

Finally, the ultrasonic test method was ranked "excellent," as it is believed that the most representative measurements can be obtained with this method. This is the most versatile method with several advantages: access required only to the top surface of the test material, tests conducted on coupons or whole sheets, and small, portable test equipment. As discussed previously, the effectiveness of the method can be improved for the determination of the velocity of the test materials.

Thickness measurements obtained under pressure can be representative of field conditions. Expected working pressures can be 
TABLE 6-Overall performance ranking.

\begin{tabular}{|c|c|c|c|}
\hline \multicolumn{2}{|c|}{ Method } & \multirow{2}{*}{$\begin{array}{l}\text { Rank } \\
\text { Poor }\end{array}$} & \multirow{2}{*}{$\begin{array}{l}\text { Remarks } \\
\text { Not representative measurement due } \\
\text { to insufficient pressure }\end{array}$} \\
\hline ASTM & $20 \mathrm{kPa}$ & & \\
\hline & $50 \mathrm{kPa}$ & Good & $\begin{array}{l}\text { Potentially representative } \\
\text { measurement, easy, pressure } \\
\text { application needed, access required } \\
\text { to both sides of material }\end{array}$ \\
\hline & $100 \mathrm{kPa}$ & Good & $\begin{array}{l}\text { Potentially representative } \\
\text { measurement, easy, pressure } \\
\text { application needed, access required } \\
\text { to both sides of material }\end{array}$ \\
\hline & $150 \mathrm{kPa}$ & Good & $\begin{array}{l}\text { Potentially representative } \\
\text { measurement, easy, pressure } \\
\text { application needed, access required } \\
\text { to both sides of material }\end{array}$ \\
\hline & $200 \mathrm{kPa}$ & Good & $\begin{array}{l}\text { Potentially representative } \\
\text { measurement, easy, pressure } \\
\text { application needed, access required } \\
\text { to both sides of material }\end{array}$ \\
\hline \multirow[t]{3}{*}{ EN } & $2 \mathrm{kPa}$ & Poor & $\begin{array}{l}\text { Not representative measurement due } \\
\text { to insufficient pressure }\end{array}$ \\
\hline & $20 \mathrm{kPa}$ & Poor & $\begin{array}{l}\text { Not representative measurement due } \\
\text { to potentially excessive pressure } \\
\text { that deforms test specimen }\end{array}$ \\
\hline & $200 \mathrm{kPa}$ & Poor & $\begin{array}{l}\text { Not representative measurement due } \\
\text { to excessive pressure that deforms } \\
\text { test specimen }\end{array}$ \\
\hline \multicolumn{2}{|c|}{ Ultrasonic } & Excellent & $\begin{array}{l}\text { Representative measurement, easy, } \\
\text { access required to one side of test } \\
\text { material, measurement on coupons } \\
\text { or whole sheet, calibration sheets } \\
\text { can be used to determine P-wave } \\
\text { velocity in geomembranes }\end{array}$ \\
\hline \multicolumn{2}{|c|}{ Magnetic } & Good & $\begin{array}{l}\text { Representative measurement, easy, } \\
\text { access required to both sides of } \\
\text { material, a setup more suitable for } \\
\text { sheet materials can be used }\end{array}$ \\
\hline
\end{tabular}

used to predict field behavior, as it was demonstrated that pressure affected thicknesses significantly. However, it must be noted that similar measurements were not obtained with the ASTM and EN methods at the same pressures $(20 \mathrm{kPa}$ and $200 \mathrm{kPa})$. Contact area affected the measurements obtained, in addition to the magnitude of the applied stresses. While, due to some similarity between the thicknesses obtained at various pressure levels, the ASTM method was deemed more effective than the EN method, whether the contact area and load effectively simulate field conditions is not known. This analysis was beyond the scope of this study. Mechanical tests are best suited for pressure application. However, it might be possible to use the nondestructive tests with pressure application as well. Weights can be added over the ultrasonic transducer to simulate varying pressures. This would not be very plausible with the existing magnetic test setup.

\section{Summary and Conclusions}

Tests were conducted to determine the thickness of smooth geomembranes using three methods: mechanical (using ASTM and

European standards), ultrasonic, and magnetic methods. The mechanical method is the standard procedure used for determining thickness of geomembranes. The ultrasonic and magnetic methods are not used commonly for geomembranes, however, they were adapted for the testing program. Tests were conducted on 15 geomembranes representing five types of polymers (HDPE, LLDPE, PVC, PP, and 
EPDM). The results of the testing program indicated that, in most cases, the thicknesses determined using the various procedures were significantly different.

The thickness measurements were affected by the level of pressures applied in mechanical tests. While the low pressures were not sufficient to flatten particularly the rigid geomembranes, the high pressures tended to compress the geomembranes excessively. Both high and low pressures prevented obtaining representative measurements. The measurements obtained using the ASTM method were more reliable than the measurements obtained with the European method. The $50 \mathrm{kPa}$ to $200 \mathrm{kPa}$ pressure range can be used with the ASTM standard tests to obtain reasonably representative measurements.

It is believed that the most reliable measurements can be obtained with the nondestructive methods (ultrasonic and magnetic). These techniques are sensitive only to the thickness of the materials (due to the nature of the test methods), and they work equally well for rigid and flexible geomembranes. Of the two methods, ultrasonic testing is better due to several advantages: it allows for testing from the top surface of geomembranes in the laboratory or in the field, and it can be used on either coupons of geomembranes or on whole sheets. Both methods can be improved to work better for geomembranes. Acknowledgment

Financial support for this study was provided by the National Science Foundation (NSF Grant No: CMS 97-01947). Materials were supplied by various manufacturers including Serrot-National Co., GSE Lining Technology Inc., HPG International Inc., Firestone Inc., and JPS Elastomerics Corp.

\section{References}

ASTM, 1998, "Standard Test Method for Measuring Nominal Thickness of Geotextiles and Geomembranes," ASTM Standard No. D 5199-95, Annual Book of ASTM Standards.

Bray, D. E. and McBride, D., Eds., 1992, Nondestructive Testing Techniques, Wiley \& Sons Inc., New York, NY.

CEN, 1995, "Geotextiles and Geotextile-Related Products-Determination of Thickness at a Specified

Pressure-Part 1: Single Layers," CEN Standard No. EN 964-1 (ISO 9863), European Standards.

Daniel, D. E. and Koerner, R. M., 1995, Waste Containment Facilities-Guidance for Construction Quality Assurance and Quality Control of Liner and Cover Systems, ASCE, Reston, VA.

Giroud, J. P., Beech, J. F., and Soderman, K. L., 1994, "Yield of Scratched Geomembranes," Geotextiles and Geomembranes, Elsevier, London, UK, Vol. 13, pp. 231-246.

Koerner, R. M., 1997, Designing with Geosynthetics, Prentice-Hall, Upper Saddle River, NJ.

Park, J. K., Sakti, J. P., and Hoopes, J. A., 1995, "Effectiveness of Geomembranes as Barriers for Organic Compounds," Proceedings of Geosynthetics '95 Conference, IFAI, St. Paul, MN, pp. 879-892.

McIntire, P., 1991, Nondestructive Testing Handbook, Volume

Seven, Ultrasonic Testing, American Society for Nondestructive Testing, Columbus, OH.

Mendenhall, W. and Sincich, T., 1995, Statistics for Engineering and the Sciences, Prentice Hall, Upper Saddle River, NJ.

Milliken, G. A. and Johnson, D. E., 1984, Analysis of Messy Data, Volume I: Designed Experiments, Lifetime Learning Publications, Belmont, CA.

Steffen, H. and Asmus, D. B., 1993, "Geomembrane Sealing of a Waste Disposal Area, Mechernich/Euskirchen, Germany,"

Geosynthetics Case Histories, G. P. Raymond and J. P. Giroud, Eds., BiTech Publishers Ltd., Canada, pp. 34-35.

Sungur, S., 1999, "Evaluation of Geomembranes Using Ultrasonic Pulse-Echo Technique,” M.S. Thesis, Department of Civil and Environmental Engineering, Wayne State University, Detroit, MI.

Yesiller, N. and Sungur, S., 2001, "Evaluation of Geomembranes Using an Ultrasonic Method,"

Geotechnical Testing Journal, Vol. 24, No. 3, pp. 273-287. 


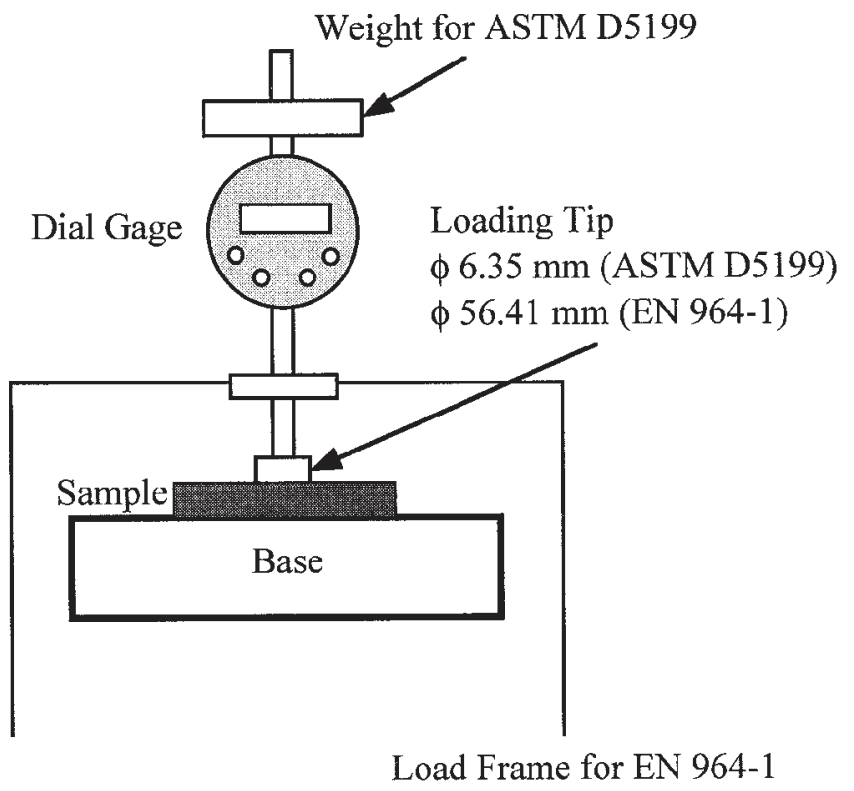

FIG. 1-Mechanical thickness determination.

Ultrasonic Transducer

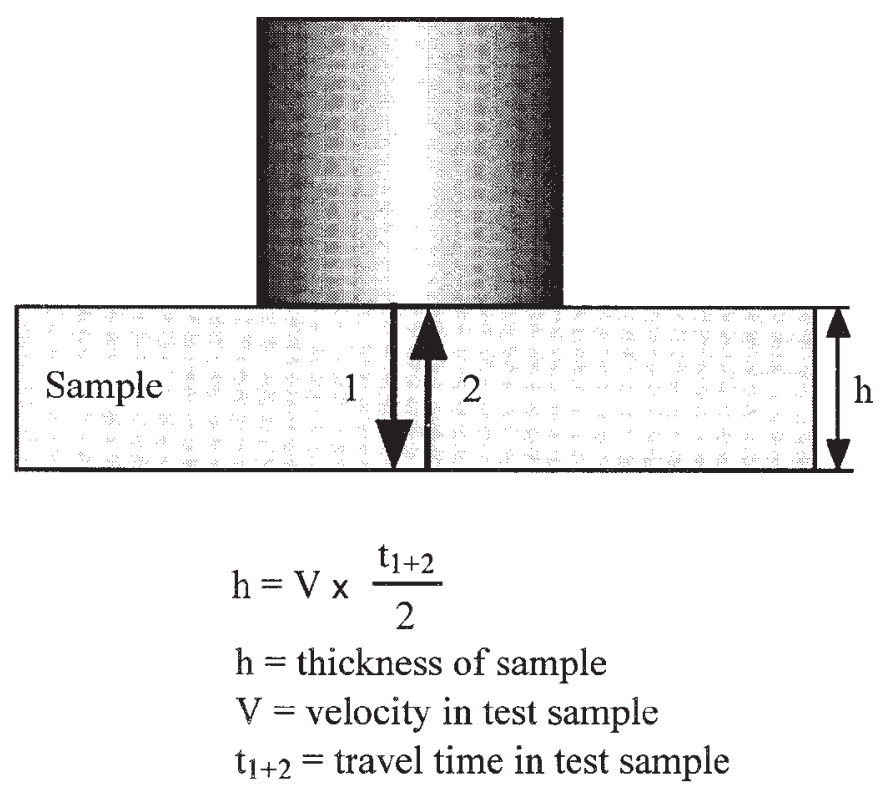

FIG. 2-Ultrasonic thickness determination. 


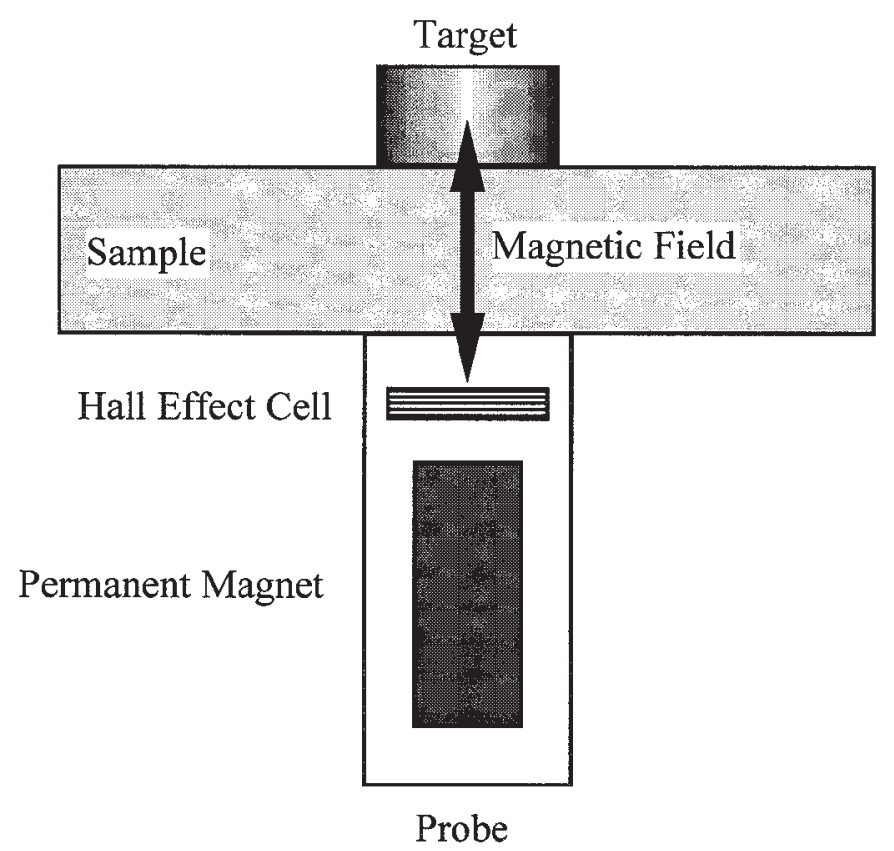

FIG. 3-Magnetic thickness determination.

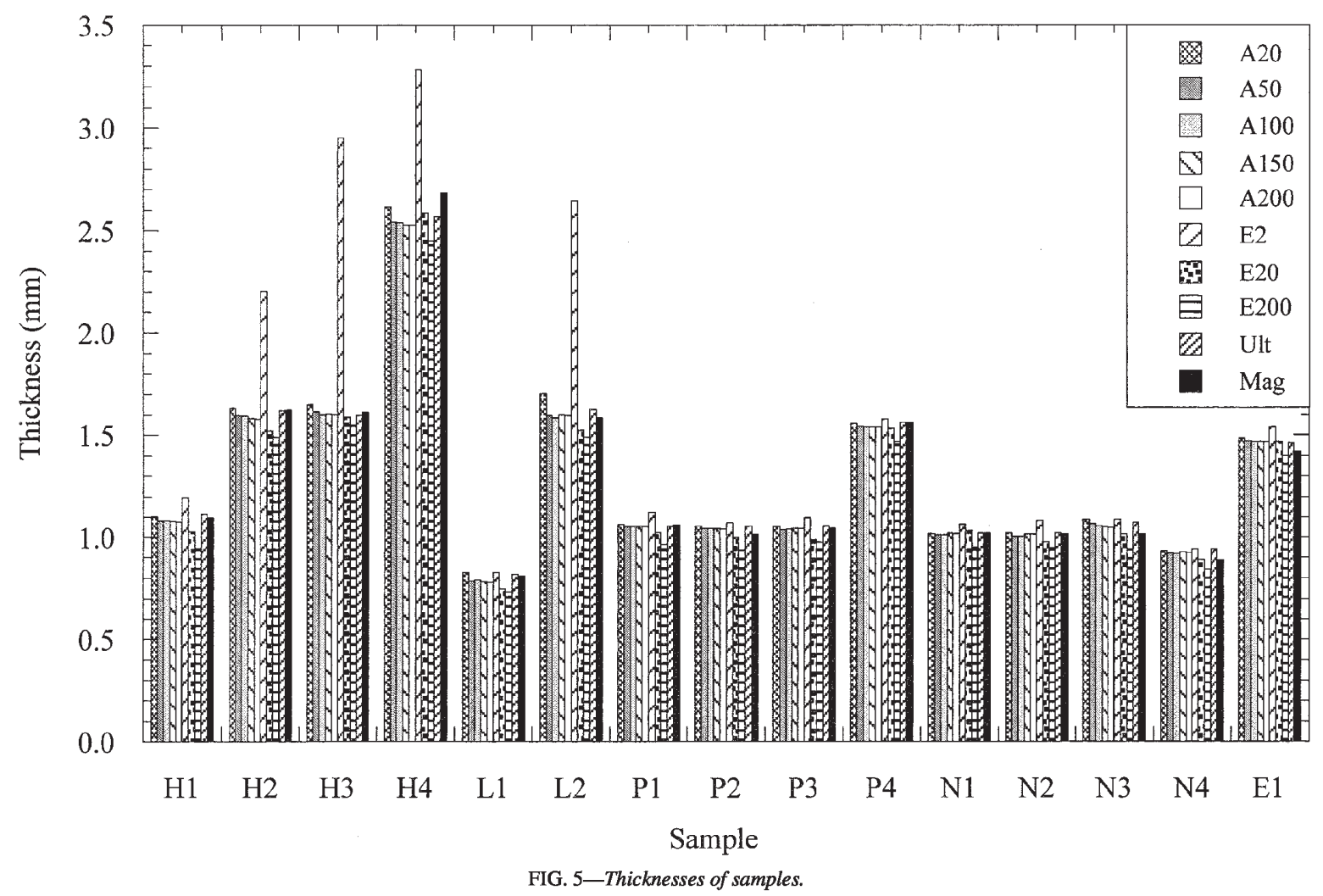

